\title{
Effect of dietary Salvia officinalis essential oil and sodium selenite supplementation on antioxidative status and blood phagocytic activity in broiler chickens
}

\author{
Miroslav Ryzner, Jana Takáčová, Klaudia Čobanová, Iveta Plachá, Katarína Venglovská, \\ Štefan Faix
}

Slovak Academy of Sciences, Institute of Animal Physiology, Košice, Slovakia

Received May 11, 2012

Accepted October 23, 2012

\begin{abstract}
Selected indicators of the antioxidant status and blood phagocytic activity were investigated in broiler chickens fed diets enriched with essential oil from Salvia officinalis and/or sodium selenite for 5 weeks. Twenty four one-day-old Ross 308 hybrid broilers were randomly divided into four groups according to dietary treatments. The control group was fed unsupplemented basal diet, whereas the feeds of three treatment groups were supplemented with essential oil $(0.05 \%)$, sodium selenite $(0.4 \mathrm{mg} \mathrm{Se} / \mathrm{kg}$ dry matter $)$ or their combination, respectively. The intake of diets containing essential oil alone or together with Se significantly elevated $(P<0.05)$ the total antioxidant status in plasma. The combination of essential oil and sodium selenite added to the basal diet resulted in significant reduction $(P<0.05)$ of superoxide dismutase activity in erythrocytes, increased activities of glutathione peroxidase in liver $(P<0.001)$ and duodenal mucosa $(P<0.05)$ compared to the control. Higher malondialdehyde concentrations in kidney tissues $(P<0.01)$ of chickens supplemented with sodium selenite were reduced by addition of essential oil to their diet. Blood phagocytic activity was significantly $(P<0.001)$ increased in both groups supplemented with selenium. The presented results demonstrate that Salvia officinalis essential oil and sodium selenite jointly added to diets had a more positive effect on the antioxidant status of broilers than when both additives were administered separately.
\end{abstract}

Sage, selenium, antioxidant enzymes, poultry

In recent years, essential oils and extracts of many plants have been studied for their antioxidant activities (Faix et al. 2007, 2009; Hussain et al. 2011). Salvia officinalis is a very popular aromatic plant well known for its wide range of medicinal effects. It has been reported that the main antioxidant activity of Salvia officinalis is attributed mainly to rosmarinic acid and the diterpene phenolics carnosol and carnosic acid (Cuvelier et al. 1996). In addition, flavonoids and other phenolic acids from Salvia officinalis may contribute to its total antioxidant activity (Lu and F oo 2001).

The endogenous activity of antioxidant enzymes may be affected by dietary factors such as selenium supplements. This essential trace element is an integral part of several specific selenoproteins which play important roles in antioxidant defense, redox regulation of gene expression, thyroid hormone metabolism, reproduction and immunocompetence development (Rayman 2000). Changes in various antioxidant enzyme activities can be used to estimate the level of oxidative stress and total antioxidant status.

The aim of this study was to investigate the effects of supplementing feed with Salvia officinalis essential oil and sodium selenite both separately and jointly, on the antioxidant status and lipid peroxide formation in plasma and tissues in chickens reared for fattening. Concurrently the birds' blood phagocytic activity was also assessed.

\section{Materials and Methods}

Twenty four Ross 308 hybrid broilers of both sexes obtained on the day of hatching from the commercial farm LP-Párovské Háje, Slovakia were randomly divided into 4 groups of 6 birds in each group according to dietary treatments. During the whole experiment, group 1 (control) was given unsupplemented basal diet (BD, BIOFED 
- HYD-02, Kolárovo, Slovakia). The diet for group 2 was the same BD enriched with Salvia officinalis essential oil at a $0.05 \%$ concentration. Group 3 received BD supplemented with selenium (Se) at a dose of $0.4 \mathrm{mg} / \mathrm{kg} \mathrm{dry}$ matter in the form of sodium selenite. The diet for group 4 consisted of BD enriched with $0.4 \mathrm{mg} \mathrm{Se} / \mathrm{kg}$ dry matter from the same sodium selenite and Salvia officinalis essential oil $(0.05 \%)$. The analysed values of Se contents in diets for groups 1 and 2 were $0.21 \pm 0.01 \mathrm{mg} / \mathrm{kg}$ dry matter, and $0.56 \pm 0.05 \mathrm{mg} / \mathrm{kg}$ dry matter for groups 3 and 4 .

At the beginning of the experiment, one-day-old chickens were placed in large wooden pens with wood shavings. All birds had free access to water and feed during the whole experiment. Temperature and lighting regimens were in accordance with standards for the care and use of animals for research purposes. The experimental protocol was approved by the Ethics Committee of the Institute of Animal Physiology of SAS and the State Veterinary and Food Office (Ro-987/08-221).

The ingredients and chemical composition of the basal diet fed to the broilers are given in Table 1. Values of the nutrient content are calculated based on data from the diet supplier. In order to maintain stable selenium status during the entire experiment, the birds were fed only one type of diet (HYD-02, control) and/or supplemented diets with Se from day 1 of their life until the end of the experiment (5 weeks). The Salvia officinalis essential oil was dissolved in sunflower oil and then gently added to the basal diet (group 2) and into BD supplemented with sodium selenite (group 4). The final concentrations of sunflower oil and Salvia officinalis essential oil were 1\% and $0.05 \%$ of the respective diets. The diets were prepared freshly every day. Salvia officinalis essential oil was provided by the Hanus company (Nitra, Slovak Republic).

Table 1. Ingredients and chemical composition of the basal broiler diet.

\begin{tabular}{lrlr}
\hline Ingredients & $\mathrm{g} / \mathrm{kg}$ & Composition & $\mathrm{g} / \mathrm{kg}$ \\
\hline Wheat & 340 & Dry matter & 891 \\
Maize & 400 & Crude protein & 190 \\
Soybean meal & 180 & Ash & 50 \\
Fish meal & 20 & Crude fibre & 35 \\
Blood meal & 10 & Calcium & 7.0 \\
Limestone & 10 & Phosphorus & 5.0 \\
Monocalcium phosphate & 8 & Lysine & 9.5 \\
Feed sodium chloride & 3 & Methionine & 4.0 \\
Premix & 19 & Methionine + cystine & 7.5 \\
Sunflower oil & 10 & Linoleic acid & 10.0 \\
& & Calculated $\mathrm{ME}$ (MJ/kg) & 12.0 \\
\hline
\end{tabular}

${ }^{1}$ The vitamin/mineral premix provided per $\mathrm{kg}$ of diet: vitamin A $12000 \mathrm{IU}$, vitamin $\mathrm{D}_{3} 4000 \mathrm{IU}$, vitamin $\mathrm{K} 4 \mathrm{mg}$, vitamin E $100 \mathrm{mg}$, thiamine $3 \mathrm{mg}$, riboflavin $9 \mathrm{mg}$, niacin $60 \mathrm{mg}$, pantothenic acid $15 \mathrm{mg}$, pyridoxine $6.0 \mathrm{mg}$, cyanocobalamin $0.04 \mathrm{mg}$, biotin $0.2 \mathrm{mg}$, folic acid $2 \mathrm{mg}$, lysine $9.5 \mathrm{~g}$, methionine $4.0 \mathrm{~g}$, Se $0.1 \mathrm{mg}, \mathrm{Zn} 100 \mathrm{mg}$, I $1 \mathrm{mg}$, Co $0.4 \mathrm{mg}$, Mn $110 \mathrm{mg}$, Cu $15 \mathrm{mg}$, Fe $120 \mathrm{mg}$

At five weeks of age, all six birds from each treatment were anaesthetised by intraperitoneal injection of xylazine (Rometar 2\%, SPOFA, Czech Republic) and ketamine (Narkamon 5\%, SPOFA, Czech Republic) using doses of 12 and $35 \mathrm{mg} / \mathrm{kg}$ body weight, respectively. After laparotomy, blood was collected into heparinised tubes by means of intracardial punction. Following euthanasia by an additional dose of anaesthetics, samples of liver, kidney and duodenal mucosa tissues were collected. The samples of blood, plasma and tissues were frozen and stored at $-70{ }^{\circ} \mathrm{C}$ until analysis.

Selenium concentrations in diets, blood and tissues were measured using the fluorometric method by Rodriguez et al. (1994). The dry matter content of diets and tissues was determined by the standard method of drying samples at $105^{\circ} \mathrm{C}$. Activity of blood glutathione peroxidase (GPx, EC 1.11.1.9) was assessed using the method of Paglia and Valentine (1967) with a Ransel kit (Randox, UK). Activities of GPx in the liver, kidneys and duodenal mucosa were measured by monitoring oxidation of $\mathrm{NADPH}+\mathrm{H}^{+}$at $340 \mathrm{~nm}$ according to Paglia and Valentine (1967). The malondialdehyde (MDA) concentrations in tissue homogenates and plasma were measured using the modified fluorometric method in accordance with Jo and Ahn (1998). Protein concentrations in the examined tissues were measured using the spectrophotometric method of Bradford (1976). Haemoglobin (Hb) content of blood, superoxide dismutase (SOD, EC 1.15.1.1) activities in the erythrocytes (Arthur and Boyne 1985) and total antioxidant status (TAS) in plasma (Miller et al. 1993) were analysed using commercial kits (Randox, UK). Phagocytic activity was measured by direct counting procedure using microspheric hydrophilic particles (Vetvicka et al. 1982). 
Statistical analysis of the differences between the groups was carried out using one-way analysis of variance with the post hoc Tukey multiple comparison test using GraphPad Software (USA). The results are expressed as mean \pm SEM and considered significant at $P<0.05$.

\section{Results}

After 5 weeks of intake of experimental diets, the concentration of Se in the blood was significantly increased $(P<0.001)$ in both groups of birds fed diets supplemented with sodium selenite. Intake of the diet with Salvia officinalis essential oil and sodium selenite combined led to significant reduction in activity of SOD in the erythrocytes of chickens $(P<0.05)$. The addition of essential oil alone $(P<0.05)$ or its addition together with Se $(P<0.01)$ to broiler diet significantly increased the total antioxidant status in plasma. The concentration of MDA in plasma was significantly lower $(P<0.05)$ in the group supplemented with sodium selenite only, compared to the control group (Table 2).

Table 2. Selenium concentration and activity of glutathione peroxidase, superoxid dismutase in red blood cells, total antioxidant status and concentrations of malondialdehyde of broilers fed diets supplemented with Salvia officinalis essential oil and sodium selenite.

\begin{tabular}{|c|c|c|c|c|}
\hline Indices & Group 1 & Group 2 & Group 3 & Group 4 \\
\hline Se in blood $\left(\mu \mathrm{g} \cdot 1^{-1}\right)$ & $104.93 \pm 7.05^{\mathrm{a}}$ & $104.70 \pm 4.53^{\mathrm{a}}$ & $154.97 \pm 7.09^{\mathrm{b}}$ & $144.97 \pm 5.50^{\mathrm{b}}$ \\
\hline \multicolumn{5}{|l|}{$\mathrm{Se}\left(\mathrm{mg} \cdot \mathrm{kg}^{-1} \mathrm{DM}\right)$} \\
\hline Liver & $2.15 \pm 0.11^{\mathrm{a}}$ & $2.11 \pm 0.13^{\mathrm{a}}$ & $2.63 \pm 0.13^{\mathrm{b}}$ & $2.59 \pm 0.04^{b}$ \\
\hline Kidney & $2.42 \pm 0.08$ & $2.55 \pm 0.11$ & $2.65 \pm 0.09$ & $2.80 \pm 0.11$ \\
\hline Duodenal mucosa & $2.55 \pm 0.09^{\mathrm{a}}$ & $2.46 \pm 0.06^{\mathrm{a}}$ & $2.98 \pm 0.09^{\mathrm{b}}$ & $3.09 \pm 0.09^{\mathrm{b}}$ \\
\hline GPx in blood $\left(\mu \mathrm{kat}^{\left.-\mathrm{g}^{-1} \mathrm{Hb}\right)}\right.$ & $2.88 \pm 0.33$ & $2.78 \pm 0.18$ & $3.73 \pm 0.34$ & $3.14 \pm 0.14$ \\
\hline \multicolumn{5}{|l|}{ GPx ( $\mu$ kat $\cdot \mathrm{g}^{-1}$ protein $)$} \\
\hline Liver & $0.34 \pm 0.04^{\mathrm{a}}$ & $0.38 \pm 0.02^{\mathrm{ab}}$ & $0.47 \pm 0.02^{\mathrm{b}}$ & $0.65 \pm 0.04^{\mathrm{c}}$ \\
\hline Kidney & $0.10 \pm 0.02^{\mathrm{a}}$ & $0.11 \pm 0.01^{\mathrm{a}}$ & $0.22 \pm 0.03^{\mathrm{b}}$ & $0.17 \pm 0.01^{\mathrm{ab}}$ \\
\hline Duodenal mucosa & $0.29 \pm 0.01^{\mathrm{a}}$ & $0.28 \pm 0.02^{\mathrm{a}}$ & $0.36 \pm 0.06^{\mathrm{ab}}$ & $0.45 \pm 0.04^{\mathrm{b}}$ \\
\hline MDA in plasma $\left(\mu \mathrm{mol} \cdot 1^{-1}\right)$ & $0.55 \pm 0.07^{\mathrm{a}}$ & $0.50 \pm 0.07^{\mathrm{ab}}$ & $0.31 \pm 0.03^{\mathrm{b}}$ & $0.46 \pm 0.04^{\mathrm{ab}}$ \\
\hline \multicolumn{5}{|l|}{ MDA (nmol $\cdot \mathrm{g}^{-1}$ protein) } \\
\hline Liver & $226.6 \pm 25.68^{a b}$ & $173.4 \pm 19.21^{\mathrm{a}}$ & $256.1 \pm 21.77^{b}$ & $191.1 \pm 13.56^{\mathrm{ab}}$ \\
\hline Kidney & $53.01 \pm 4.10^{\mathrm{a}}$ & $48.77 \pm 2.56^{\mathrm{a}}$ & $81.97 \pm 5.14^{\mathrm{b}}$ & $60.35 \pm 3.70^{\mathrm{a}}$ \\
\hline Duodenal mucosa & $50.24 \pm 6.19$ & $32.31 \pm 3.43$ & $32.62 \pm 6.19$ & $43.37 \pm 6.51$ \\
\hline $\mathrm{SOD}$ in $\mathrm{RBC}\left(\mu \mathrm{kat} \cdot \mathrm{g}^{-1} \mathrm{Hb}\right)$ & $22.28 \pm 0.62^{\mathrm{ab}}$ & $18.51 \pm 1.31^{\mathrm{ac}}$ & $25.09 \pm 1.88^{\mathrm{b}}$ & $17.17 \pm 0.51^{\mathrm{c}}$ \\
\hline TAS in plasma $\left(\mathrm{mmol} \cdot \mathrm{l}^{-1}\right)$ & $1.25 \pm 0.06^{\mathrm{a}}$ & $1.86 \pm 0.07^{\mathrm{b}}$ & $1.68 \pm 0.21^{\mathrm{ab}}$ & $2.08 \pm 0.15^{b}$ \\
\hline
\end{tabular}

Group 1 - basal diet (BD), group 2 - BD with Salvia officinalis essential oil, group 3 - BD with sodium selenite, group 4 - BD with Salvia officinalis essential oil and sodium selenite

GPx - glutathione peroxidase, SOD - superoxid dismutase, RBC - red blood cells, TAS - total antioxidant status, MDA - malondialdehyde, DM - dry matter, SEM - standard error of the mean

Results are presented as mean \pm SEM

Values in a row not sharing common letters $(\mathrm{a}, \mathrm{b}, \mathrm{c})$ are significantly different $(P<0.05)$

As shown in Table 2, supplementation of sodium selenite into diets for broilers resulted in a significant increase in the Se content in tissues of the liver $(P<0.05)$ and duodenal mucosa $(P<0.01)$. Salvia officinalis essential oil and sodium selenite jointly added to diets significantly elevated the GPx activities in the liver $(P<0.001)$ and duodenal mucosa $(P<0.05)$ compared to those of birds fed diets without Se. However, GPx activity in kidney tissue was significantly higher $(P<0.01)$ in chickens fed a diet containing sodium selenite only. 
Table 3. Blood phagocytic activity and its index in broilers fed diets supplemented with Salvia officinalis essential oil and sodium selenite.

\begin{tabular}{lcccc}
\hline Indices & Group 1 & Group 2 & Group 3 & Group 4 \\
\hline Phagocytic activity (\%)* & $40.50 \pm 0.42^{\mathrm{a}}$ & $42.13 \pm 0.72^{\mathrm{a}}$ & $48.75 \pm 0.53^{\mathrm{b}}$ & $49.00 \pm 0.42^{\mathrm{b}}$ \\
Index of phagocytic activity** & $2.15 \pm 0.09$ & $2.06 \pm 0.04$ & $2.20 \pm 0.09$ & $2.08 \pm 0.08$ \\
\hline
\end{tabular}

Group 1 - basal diet (BD), group 2 - BD with Salvia officinalis essential oil, group 3 - BD with sodium selenite, group 4 - BD with Salvia officinalis essential oil and sodium selenite

"Number of white cells containing at least three engulfed particles/100 white cells

${ }^{* *}$ Number of engulfed particles per total number of neutrophils and monocytes observed

Results are presented as mean \pm SEM

Values in a row not sharing common letters $(\mathrm{a}, \mathrm{b}, \mathrm{c})$ are significantly different $(P<0.05)$

Intake of the diet containing Salvia officinalis essential oil alone significantly decreased the MDA concentration $(P<0.05)$ in liver tissue compared to group 3, given the diet supplemented with selenium. Kidney tissue showed significant increase in MDA concentrations $(P<0.01)$ in the group supplemented with sodium selenite only (Table 2$)$.

Sodium selenite supplementation of both diets (group 3 and 4 ) resulted in significantly higher $(P<0.001)$ phagocytic activity of blood (Table 3 ).

\section{Discussion}

The combination of Salvia officinalis essential oil and sodium selenite led to significantly the highest activity of GPx in the liver. Salvia officinalis essential oil added to broiler diets together with sodium selenite could be used to reduce the effects of oxidative processes in the duodenal mucosa due to their beneficial effect on glutathione peroxidase activity.

In our study, the MDA concentration in the broiler's plasma was found to be significantly decreased by sodium selenite supplementation, whereas it was significantly elevated in kidney tissue. In contrast, the opposite situation was found in the kidney tissues of laying hens when the MDA content was reduced by sodium selenite and Se-yeast supplementation, but its production in the liver was inhibited by the organic form of Se (Petrovič et al. 2006). We have no rational explanation for higher lipid peroxidation in the kidney tissues in the group given sodium selenite; however, it may be connected with the pro-oxidative properties of sodium selenite (Spallholz 1997) causing disturbance in the oxidant balance in this tissue. In any case, the harmful effects of selenite which were accompanied by oxygen free radical formation in kidney tissue were eliminated by addition of Salvia officinalis essential oil into the diet of broilers. According to the results obtained by Hussain et al. (2011), Salvia officinalis essential oil demonstrated excellent radical scavenging activity. It has been reported that in spite of the fast metabolic conversion and excretion of essential oils, they can accumulate in various tissues in chickens if the administration is continuous (Lee et al. 2004). For these reasons, we can suppose that the antioxidative properties of Salvia officinalis essential oil components are responsible for the adjustment of lipid peroxidation in the kidney tissue. With regard to the biological properties of essential oils, it should be kept in mind that this is a complex mixture of many molecules and their biological effects are the result of a synergism of all the molecules. It is possible that the activity of the main components is modulated by other minor molecules (Hoet et al. 2006).

The antioxidant ability of Salvia officinalis oil has been evaluated and confirmed using various assays (Miguel et al. 2011). Measurements of plasma antioxidants intended to assess the total antioxidant status in vivo showed higher values in broilers fed the diet supplemented with Salvia officinalis essential oil in our study. Faix et al. (2007) found 
similar results with Thymi aetheroleum and Origani aetheroleum (both at a $0.1 \%$ concentration) in mice.

The combined treatment of Salvia officinalis essential oil and sodium selenite caused significantly lower activity of SOD in blood erythrocytes compared to that of broilers fed a basal diet or supplemented with sodium selenite only. Lin et al. (2000) reported that polyphenols proved to be effective superoxide radical scavengers. Mainly rosmarinic acid derivates from sage possess strong superoxide scavenging activity. Flavonoid glycosides have weaker superoxide scavenging activities than phenolic acids (Lu and F oo 2001).

Evaluation of the phagocytic activity revealed significantly higher percentages in both our groups on diets supplemented with sodium selenite. Similarly, Milad et al. (2001) showed that selenium administration led to significant effects on the phagocytic activity index of leukocytes and neutrophils. Szabóová et al. (2008) reported that Salvia officinalis extract application to rabbits resulted in higher phagocytic activity in their blood. It has been observed that intake of diets containing different doses of essential oil increased the blood phagocytic activity, and may thus have immunostimulatory effect in broiler chickens (Faix et al. 2009). Together, essential oil from Salvia officinalis and Se supplementation affected the immune system, as indicated by higher blood phagocytic activity in our study.

In conclusion, the results of this experiment demonstrate that Salvia officinalis essential oil used as a dietary supplement alone or in combination with sodium selenite possesses antioxidant properties through the ability to activate antioxidative enzymes, and significantly increases the total antioxidant status of broiler chickens. Essential oil from Salvia officinalis can be considered as a source of antioxidants that could be used for supplementation of poultry feed, in order to prevent or delay formation of oxygen free radicals in chickens reared for fattening.

\section{Acknowledgement}

This study was supported by the Grant Agency for Science (VEGA) of the Slovak Republic, Grant No. 2/0010/10, and by the Slovak Research and Development Agency, Slovak Republic, Grant No. APVV-0399-07.

\section{References}

Arthur JR, Boyne R 1985: Superoxide dismutase and glutathione peroxidase activities in neutrophils from selenium deficient and cooper deficient cattle. Life Sci 36: 1569-1575

Bradford M 1976: A rapid and sensitive method for the quantification of microgram quantities of protein utilizing the principle of protein-dye binding. Anal Biochem 72: 248-254

Cuvelier ME, Berset C, Richard H 1996: Antioxidant activity and phenolic composition of pilot-plant and commercial extracts of sage and rosemary. J Am Oil Chem Soc 73: 645-652

Faix Š, Faixová Z, Plachá I, Koppel J 2009: Effect of Cinnamomum zeylanicum essential oil on antioxidative status in broiler chickens. Acta Vet Brno 78: 411-417

Faix S̆, Juhas S̆, Faixová Z 2007: The effect of essential oil intake on changes of plasma antioxidant status in mice. Acta Vet Brno 76: 357-361

Hoet S, Stevigny C, Herent MF, Quetin-Leclercq J 2006: Antitrypanosomal compounds from leaf essential oil of Strychnos spinosa. Planta Med 72: 480-482

Hussain AI, Anwar F, Iqbal T, Bhatti IA 2011: Antioxidant attributes of four Lamiaceae essential oils. Pak J Bot 43: $1315-1321$

Jo C, Ahn DU 1998: Fluorometric analysis of 2-thiobarbituric acid reactive substances in turkey. Poultry Sci 77: 475-480

Lee KW, Everts H, Beynen AC 2004: Essential oils in broiler nutrition. Int J Poult Sci 3: 738-752

Lin JK, Chen PC, Ho CT, Lin-Shiau SY 2000: Inhibition of xanthine oxidase and suppression of intracellular reactive oxygen species in HL-60 cells by the theaflavin-3,3'-digallate, (-)-epigallocatechin-3-gallate, and propyl gallate. J Agr Food Chem 48: 2736-2743

Lu Y, Foo LY 2001: Antioxidant activities of polyphenols from sage (Salvia officinalis). Food Chem 75: $197-202$

Miguel G, Cruz C, Faleiro ML, Simões MTF, Figueiredo AC, Barroso JG, Pedro LG 2011: Salvia officinalis L. essential oils: effect of hydrodistillation tiem on the chemical composition, antioxidant and microbiological activities. Nat Prod Res 25: 526-541 
Milad K, Rácz O, Šipulová A, Bajová V, Kováč G 2001: Effect of vitamin E and selenium on blood glutathione peroxidase activity and some immunological parameters in sheep. Vet Med Czech 46: 1-5

Miller NJ, Rice-Evans C, Davies MJ, Gopinathan V, Milner A 1993: A novel method for measuring antioxidant capacity and its application to monitoring the antioxidant status in premature neonates. Clin Sci 84: 407-412

Paglia DE, Valentine WN 1967: Studies on quantitative and qualitative characterization of erythrocyte glutathione peroxidase. J Lab Clin Med 70: 158-169

Petrovič V, Boldižárová K, Faix Š, Mellen M, Arpášová H, Leng L' 2006: Antioxidant and selenium status of laying hens fed with diets supplemented with selenite or Se-yeast. J Anim Feed Sci 15: 435-445

Rayman MP 2000: The importance of selenium to human health. Lancet 356: 233-241

Rodriguez EM, Sanz MT, Romero CD 1994: Critical study of fluorometric determination of selenium in urine. Talanta 41: 2025-2031

Spallholz JE 1997: Free radical generation by selenium compounds and their prooxidant activity. Biomed Environ Sci 10: 260-270

Szabóová R, Lauková A, Chrastinová L, Simonová M, Strompfová V, Haviarová M, Plachá I, Faix Š, Vasilková Z, Chrenková M, Rafay J 2008: Experimental application of sage in rabbit husbandry. Acta Vet Brno 77: 581-588

Vetvicka V, Fornousek L, Kopecek J, Kaminkova J, Kasparek L, Vranova M 1982: Phagocytosis of human blood leukocytes, a simple micro-method. Immunol Lett 5: 97-100 